\title{
Cooperation among Institutions of the Soviet Union and Cuba: Accomplishments between 1972 and 1990
}

\author{
Tomás López Jiménez \\ University of Informatics Sciences \\ Carretera a San Antonio de los Baños Km. 21/2, Torrens, Boyeros \\ Ciudad de la Habana, 19370, Cuba
}

\begin{abstract}
This work provides a landscape on the manner in which Cuba and the Soviet Union had cooperated in the computing field between 1972 and 1990. It highlights some of the important milestones between the two nations including Cuban membership on the Council for Mutual Economic Assistance, the COMECOM, and its activities in the Coordinating Committee for Multilateral Export Controls. It also addresses Cuba's relationship with the Former Soviet Union after 1990.
\end{abstract}

Keywords: Computing in Cuba, Soviet Union, COMECOM, CMEA.

\section{Introduction}

The SoRuCom 2006 Conference has offered a unique opportunity to exchange information on contributions to electronic computing (EC) from the Former Soviet Union (FSU). These facts, both worthy and significant for students, professors, and professionals of its disciplines worldwide, need further documentation by the history of computing.

This conference occurs sixty years after the public demonstration of the ENIAC computer, immediately after World War II and three years before the establishment of the Council for Mutual Economic Assistance (CMEA) in 1949, under the leadership of the FSU. The intermingling of causes and effects among these events, their true motivations, and their usefulness for humanity are still partially and barely researched or informed. In fact, the effects induced in the CMEA countries by the multilateral collaboration constitute part of the history of the scientific development of the EC promoted by the FSU, which dedicated special efforts to this collaboration; thus, empowering it with the creation in 1969 of the Intergovernmental Commission for Collaboration in the field of EC (ICCEC). Therefore, part of the accomplishments of the joint works is also part of Soviet and Russian computing history.

Cuba became a member of CMEA in 1972, three years after the institution of the ICCEC, over twelve years from the beginning of bilateral relations with the FSU. This paper discloses some elements of this bilateral history on EC. First, we explore its principal landmarks in Cuba since 1972; then we also reflect on some of the main achievements from the rich and friendly Cuban-Soviet collaboration in this field. 


\section{Development of the EC in Cuba Before Its Admission to COMECOM}

\subsection{Computing in Cuba Before 1 January 1959}

When the Cuban Revolution triumphed on 1 January in 1959, the knowledge of EC did not exist in a practical sense in the country. This was the status even though there was a vast tradition using tabulating and accounting machines for data processing, including the use of some electronic ones since 1957 that included two IBM 407 machines and a UNIVAC 120. Actually, some private schools, mostly Cuban, prepared specialists for their use.

By the end of 1958, the first electronic computer appeared in Cuba; it was a first generation IBM RAMAC 305 with the first magnetic discs in the world, when they still constituted a world novelty [1]. One should note that in 1927 IBM opened a business office in Cuba, the $27^{\text {th }}$ outside the borders of the USA; in fact, it placed in the $16^{\text {th }}$ position among its main landmarks of foreign business concerning the installation of tabulators in Havana in 1927. Cuba was the thirteenth country to which they exported their equipment [2]. The Cuban government confiscated IBM Cuba in 1961. These facts are evidence that in 1959 there were in Cuba some advanced components of EC. In addition, the minimum necessary conditions for starting its development were already in operation and the country exerted a certain attraction for IBM [3]. When the United States government broke its diplomatic relations with the Cuban government in 1961, it imposed a ferocious blockade on the country that started in February of 1962, thereby making access to their technology on the island very hard or almost impossible.

\subsection{First Steps: The 1959-1967 Period}

In 1959, a deep educational reform started in the country. In January of 1960, Commander-in-Chief Fidel Castro stated, "The future of our country has to be necessarily a future of scientific men, a future of thinking men." Later on in March of 1962, the Minister of Industries, Commander Ernesto Che Guevara pointed toward electronics as one of the four important lines for the development of the country. That same year the government organized the Automation and Electronics Division with the mission of developing research and working experiences in electronics, cybernetics, automation, and computing [4].

In 1964, the National Calculus Center (CNC) at the University of Havana (UH) acquired the British second-generation computer - the Elliott 803B; the university completed its installation in 1965. The School of Mathematics and other areas of the university, in collaboration with the Department of Applied Mathematics of the Central Planning Board (JUCEPLAN), as well as other institutions, developed applications for the optimization of transportation, diets optimization and management of chicken plants, numerical weather forecasts, and other areas that benefited the country.

The sugar industry developed important applications for the period as part of its perspective plan to produce ten million tons of sugar in 1970. It all started with the RAMAC and until 1966, it progressively used the Elliot 803B in applications with 
regression and linear programming models in order to optimize the harvest period and the composition of sugar cane varieties per plant, the operational control, as well as the optimization of the transportation of the sugar cane among other areas.

\subsection{The Essential Conditions Were Created: The 1968-1971 Period}

Between 1968 and 1976, the following parallel and complementary paths directed the Cuban development of the EC:

1. Under the responsibility of the JUCEPLAN, the board fostered planning and statistical centralized control over the country plans and programs and the 1970 population and housing census. The National Calculus Plan (PNC) was created for this program, based on the importation of technology and technical assistance. In 1969, the Electronic Calculus Division was also organized.

2. The second path foresaw empowering the scientific and technological national development. Personally conceived and encouraged by Commander-in-Chief Fidel Castro by the end of 1968, it was assigned to the UH, with an immediate objective of developing the first Cuban computer, a real challenge for a very young scientific policy [5].

3. The third path was under the responsibility of the national defense and security organisms; it also included a tight collaboration with the other two.

The PNC reached agreements in 1968 with the French government in 1970 for the supply of two second-generation SEA 4000 computers. From 1972 on, there were other supplies of two mainframes IRIS 50 and some minicomputers IRIS 10, both were third-generation models. Some of the minis were remote satellite terminals, three of them were destined to universities and the rest to specialized organizations, mainly places which were already using the Cuban minis CID 201A and B by the time they received the French minis.

On April 1969, the UH created the Digital Research Center (CID) with the mission of developing the Cuban computer. On 18 April of 1970, the first Cuban minicomputer, the CID 201, became operational. It was a third-generation model, with DTL integrated circuits, a $4 \mathrm{~K}$ memory with 12-bit ferrite core words. Its architecture did not follow a full line of compatibility with the PDP 8. They connected a teletype to it with a paper tape I/O system at $33 \mathrm{bits} / \mathrm{sec}$. In October of 1970, they also connected to it an audio compact cassette tape recorder at 300 bauds, ten times faster than the paper tape, and in addition, an auxiliary memory of up to $64 \mathrm{~K}$ words by which its applicability, productivity, and reliability were largely increased [6]. This achievement occurred five years before reports of the first standards for similar use in microcomputers; it became an alternative for the expensive flexible disk units in use by then [7]. Eighteen units of the CID 201 were manufactured and delivered between the end of 1970 and 1972, under the name of CID 201A, a technological variant whose only difference relied on the casing.

The fact that the original DEC systems were inaccessible for Cuba and the lack of compatibility between the CID 201A and PDP 8 programs became an extraordinary challenge for the CID researchers. By the end of 1970, the local software of the CID 201 included a basic binary and octal input/output system, an arithmetic package of integer and floating point, a LEAL 201 compiler (Algorithmic Language - auto code 
of indigenous design in polish and symbolic notation, which followed some of the concepts of Autocode Elliot 803B). By 1972, they added an interpretive compiler of a simplified FORTRAN and some other programs. Additionally in 1972, the experimental CID 202 minicomputer went into service with its research objectives. It had a $16 \mathrm{~K}$ ferrite memory, with 16 bits words, an original architecture with the novelty of running two simultaneous programs with their respective operators.

By the end of 1972 Cuba saw the completion of the new family of minicomputer CID 201B; however, it was not wholly compatible with the PDP 8. It doubled the $201 \mathrm{~A}$ speed, with a memory unit of up to $32 \mathrm{~K}$ words through $4 \mathrm{~K}$ modules, eight auto index registers by module over the first eight address of each zero page, interruption system for the I/O devices and a bus for direct access magnetic disks and tapes. The computer accommodated various software packages that included an original powerful FORTRAN IV compiler. In October 1972 witnessed the definition of the next generation of minicomputers, the CID 300; it would be wholly compatible in software with the PDP 11, following DEC's more innovative tendencies.

In 1973, CID started a minicomputers factory in the industrial area of the V. I. Lenín Vocational School based on its own indigenous expertise. Students had full participation in the production lines as part of their training and vocational development. This practice proved fruitful for them as they continued their higher education studies as engineers or mathematicians with early deep and advanced theoretical and practical knowledge on computing.

To summarize, therefore, in $1970 \mathrm{UH}$ launched its Computing Commission with a national reach. It strengthened and diversified its research program, incorporating others for the industrial development as well as the applications and fast development of the teaching of the computing disciplines in the national education system. In 1970 the degree in the Computing Sciences began at the School of Mathematics of the UH and at the Central University; numerous faculties and colleges introduced the subjects of FORTRAN IV Programming and Analysis. By 1971 the UH introduced the area of computing engineering for students who had finished their fourth year in telecommunication or in automatic controls. The CID strengthened its academic department as it created courses on operation, programming, and applications, starting a master degree program in digital systems in 1971, in conjunction with Canadian universities.

\section{Main Characteristics and Accomplishments of Cooperation Work in EC between the Institutions of the FSU and Cuba (1972-1990)}

\subsection{EC Tendencies at the Beginning of the Socialist Collaboration}

In 1969 the CMEA adopted the agreement to create the socialist central computers (CC - mainframes), five years after the IBM 360 generation of computers appeared. The conclusion of agreements for minicomputers occurred in 1974, nine and four years after the launching of the PDP 8 and PDP 11 respectively, when the microprocessor and integrated memories market had just been born, with a fast 
incorporation to EC. Local tendencies and needs reinforced the popularization and massive use of computing because it provided greater power at lesser costs. It was already an extraordinary challenge to reach the world upper levels; to stay abreast and to keep a reasonable follow-up and to prevent the relative backwardness from increasing was a very difficult goal.

\subsection{First Steps in the EC Collaboration between the FSU and Cuba}

Cuba joined the CMEA three years after the agreement to develop the CC systems of the Unified Systems of Electronic Computer Machines. The Cubans already had some essential scientific and industrial knowledge in order to consider higher-level objectives in EC, independently of its economy, which did not yet surpass the characteristics of a poor developing country. That is the reason the world classified Cuba as one of the least developed countries of the signing members.

In 1974 when they reached agreement for the development of the System of Mini Electronic Computer Machines (SM MCE), Cuba, represented by CID as a national head organization, was one of its founding countries [8]. That is how the collaboration with the Soviet INEUM started, the leading multilateral organization of the project SM.

With the creation of the National Institute of Automated Systems and Computing Techniques in 1976, a member of the Council of Ministers, the Cuban-FSU collaboration in EC was prioritized at a high national level, thereby strengthening and intensifying the relations and compromise among institutions and peoples of both countries [9]. The FSU signed the Cuban specialization in central processors, video terminals, keyboards for video terminals and microcomputers, as well as software products for the SM systems.

\subsection{Main Projects and Joint Outcomes}

The Cuban-Soviet projects were part of the minicomputer generation of the SM second architecture, because it included among its guidelines the full compatibility of programs with the PDP 11 family of computers [10]. This would facilitate a more effective contribution to Cubans, due to their experience and knowledge of the DEC lines. This accomplishment occurred despite the fact that the economic blockade, to which they added the CoCoM regulations among others, impeded the access to original products and documentation [11].

The CID participated in the SM 3 and SM 4 development, including the joint startup of the first prototypes of the SM 3 in 1976, carried out by INEUM. The Cuban variant of the SM 3, the CID 300/10, reached a conclusion in 1976; its national tests began in 1977 and in the international essay, they codified it as SM 2301, which was in serial production between 1977 and 1988 with a total amount of 410 systems. In addition, they created a Cuban prototype of the SM 4 called the CID 300/20. They also developed the decimal arithmetic processor for CID 2201 (SM 50/02).

From 1974 to 1990, Cuba developed numerous alphanumeric and graphic video terminals, supplying more than 12,000 units to Soviet institutions in addition to 
satisfying the Cuban needs [12]. Among the main objectives stated was the gathering of experience with the raster-scan technique, incorporated to the CID 702 (SM 7203) in 1975-1976. They used advanced controllers through analogs from Intel 8275 and 8279. The functional analogy with the most advanced models of leading marks, with solutions and their own resources constituted key objectives. The CID 7205 (SM 7213) emulated the DEC VT 52 and they incorporated a graphic regimen to this model. Other terminals emulated were the VT 100 and the VT 240 [13].

Between 1984 and 1990, various models of keyboards were developed and manufactured, fulfilling the SM standards and guaranteeing the functional analogy with those of IBM PC, VT 100, VT 240, and others. They used in abundance the contact key by electrically conductive rubber; Soviet institutions received dozens of thousands of keyboards from Cuba. The Cuban and Soviet specialists, who jointly developed these projects, reached a favored place among the keyboard and terminal video designers for SM.

With the software for SM, they obtained important results, among them the COBOL CID 300 compiler, tested for the SM in 1979, and widely used with Soviet minicomputers. Some other software products were the management system GES300, the multi terminal SMT300, the dBASE300, the UNIX tools and the COMUNIX CID300-IBM.

\section{Conclusion}

Nowadays, both the organizations and the Cuban specialists that worked closely together for more than eighteen years with their Soviet siblings are devoted to other development and application of modern informatics, where by some ways many of the results of that long and fruitful collaboration remain. In the 1980s, the ICID began a gradual redirection towards the development and production of high-level medical equipment and applications for diagnosis, intensive care, rehabilitation, and reaching a very high prestige and quality in that specialty. These equipment and applications are used profusely in the national health system and are exported to several countries. A similar process happened with complex automation, now specializing in applications for the sugar industry, the medical and the pharmaceutical industries, and the tourist facilities as well.

Certain factors, beyond the objectives of the current work, caused the advance and the level of the results of the socialist CE to lag behind in respect to the advance of leader countries at world levels. Nevertheless, in that period the collaborative work made unquestionable and everlasting contributions to human development. Among them are the contributions to scientific knowledge and the graduation of a great mass of highly qualified specialists, that were in those moments placed at the disposal of countless and diverse institutions. It is an irrefutable fact that as a result of this bilateral collaboration, at least modest contributions were added to those objectives, along with the friendship and mutual knowledge achieved among Cubans and formerly Soviet citizens, forever Russian citizens. The history stated here and much more are part of the history of computing of these countries. 


\section{References}

1. See IEEE Santa Clara Valley Section, Dedication (May 26, 2005), http://www.ieee.org/organizations/history_center, reports that IBM 305 RAMAC was commercial from (September 4, 1956)

2. More FAQ about IBM, http: / / www-03.ibm.com/ibm/history/documents/pdf/faq.pdf

3. Barquin, R.C.: The State of Computation in Cuba - DATAMATION, pp. 69-72 (December 1973)

4. Sáenz, T., Capote, E.: Ciencia y tecnología en Cuba. La Habana, Editorial de Ciencias Sociales (1989)

5. López, J., Tomás: Cubans have got a special gift for mastering the computing - Juventud Rebelde Journal (March 23, 2006)

6. Ball-llovera, D., Antonio - CID report - 1970 and later documents (1970)

7. KCS (Kansas City Standard) o BYTE standard, BYTE February, 1976. A little later the Processor Technology Corporation published the popular CUTS - Computer Users' Tape Standard - which work at 300 or 1200 bauds, http://en.wikipedia.org/wiki/Kansas_City_standard

8. Egorov, G.A.: SM MCE. Detailed Scheme (July 2, 2002), http://www. computermuseum.ru/histussr/sm_evm2.php

9. Nitusov, A.: Computing Technique of the CMEA countries, Is a very interesting paper, but information about Cuba is not enough accuracy (November 2005),

http://www. computer-museum.ru/histussr/sev_it.htm

10. Filinov, E.N.: System mini ECM (SM MCE), http://www.computermuseum.ru/histussr/sm_evm.htm

11. CoCom: Coordinating Committee for Multilateral Export Controls. CoCom was established during the Cold War to put an embargo on Western exports to East Bloc countries, http://en.wikipedia.org/wiki/CoCom

12. The XXX Anniversary of the creation of the first Cuban computer, the CID 201, publicized in CD by ICID (April 2002)

13. ICID - Instituto Central de Investigaciones Digitales, the new name of CID, modifying its category in the decade of the 80s (1969) 